\title{
Structural Studies of Human ATP-Specific Succinyl-CoA Synthetase
}

\author{
Ji Huang, Marie E. Fraser \\ Department of Biological Sciences, University of Calgary, Calgary, Alberta T2N 1N4
}

Succinyl-CoA synthetase (SCS) catalyzes the only substrate level phosphorylation in the citric acid cycle: Succinyl-CoA + NDP $\rightleftharpoons$ Succinate $+\mathrm{CoA}+$ NTP in the presence of magnesium ions. In mammals, SCS is a heterodimer with $\alpha$ and $\beta$ subunits and nucleotide-specific isoforms of SCS exist: one is ATP-specific SCS (ATPSCS) and the other one is GTP-specific SCS (GTPSCS). ATPSCS is coded by genes SUCLG1 and SUCLA2 and GTPSCS is coded by genes SUCLG1 and SUCLG2. SUCLG1 codes for the common $\alpha$ subunit. The specificity of SCS for either ATP/ADP or GTP/GDP is determined by the $\beta$ subunit (1). Deleterious mutation in the gene SUCLA2 has been reported to cause diseases, such as encephalomyopathy and mitochondrial DNA depletion (2), and mutations in the genes SUCLG1 and SUCLA2 led to elevated levels of methylmalonic acid (3). The structures of GTPSCS and its complexes have been well studied over the decades. But there is no structure of ATPSCS or its complexes in the Protein Data Bank. Knowing the structure of the complex of ATPSCS with ATP-Mg ${ }^{2+}$ will be helpful in further understanding the mechanism of the SCS-catalyzed reaction.

Previous studies of full length human ATPSCS did not succeed in obtaining high resolution structures. A study of truncated human ATPSCS, with only the ATP-binding domain (Abd-ATPSCS), was proposed in order to reveal the interactions between ATPSCS and ATP- $\mathrm{Mg}^{2+}$. Abd-ATPSCS was produced in E. coli BL21(DE3) and purified through a three-step chromatographic purification. Abd-ATPSCS was cocrystallized with ATP and magnesium ions at a high concentration of polyethylene glycol 3350. The crystal diffracted to $\sim 2.8 \AA$.

\section{References:}

1. Johnson, J. D., Muhonen, W. W., and Lambeth, D. O. (1998) Characterization of the ATPand GTP-specific succinyl-CoA synthetases in pigeon. The enzymes incorporate the same alpha- subunit. J. Biol. Chem. 273, 27573-27579.

2. Elpeleg, O., Miller, C., Hershkovitz, E., Bitner-Glindzicz, M., Bondi-Rubinstein, G., Rahman, S., Pagnamenta, A., Eshhar, S., and Saada, A. (2005) Deficiency of the ADP-forming succinyl- CoA synthase activity is associated with encephalomyopathy and mitochondrial DNA depletion. The American Journal of Human Genetics. 76, 1081-1086.

3. Navarro-Sastre, A., Montoya, J., Unceta, M., Martinez, M. J., Briones, P., Ribes, A., Tort, F., Garcia-Villoria, J., Pons, M. R., Nascimento, A., Colomer, J., Campistol, J., Yoldi, M. E., and López-Gallardo, E. (2012)

Mitochondrial DNA depletion syndrome: New descriptions and the use of citrate synthase as a helpful tool to better characterise the patients. Mol. Genet. Metab.

107, 409-415. 